\title{
EXPERIMENTAL RESEARCH ON QUALITY AND ENERGETIC INDICES OF EQUIPMENT FOR OPENING AND COMPARTMENT ALIZING WATERING FURROWS
}

\author{
Marius Oprescu $^{1}$, Sorin-Stefan Biris ${ }^{2}$, Petru Cardei $^{1}$, Virgil Muraru ${ }^{1}$ \\ ${ }^{1}$ National Institute of Research-Development for Machines and Installations Designed to Agriculture \\ and Food Industry, Romania; ${ }^{2}$ University Politehnica of Bucharest, Romania \\ biris.sorinstefan@gmail.com, petru_cardei@yahoo.com \\ icsit@inma.ro, relatii.publice@upb.ro
}

\begin{abstract}
The article presents synthetic experimental results regarding the qualitative and energetic indices of the equipment for opening and compartmentalizing watering furrows EOCWF). The equipment generates compartmentalized irrigation canals using two working organs: the first, the main working body that forms the initial profile, the lister (double mouldboard) or double mouldboard, and the second, a paddle that rectifies the section of the canal and mainly performs the compartmentalization of the canal. The qualitative indices to which the results presented in this chapter refer are the dimensions of the cross-section and the length of the irrigation channel compartment. Qualitative indices are studied for four variants of secondary organ formation, the palette. A statistical method for selecting the best pallet variant is presented, relative to the experimental conditions. The working method developed for the selection of the optimal palette variant can be used in a future experimental study for various types of soils, with various humidity and different working speeds. The mode of experimentation is briefly explained. A statistical analysis of the experimental data is made. The statistical analysis contains both a descriptive and an inferential part on the experimental data population consisting of the dimensions of the irrigation channel opened by the equipment used. The experimental data come from two variants of equipment for opening channels, each operating in turn with four types of blades for rectifying the open channel through rarity. Finally, based on objective functions developed by the authors, optimal solutions to the working process of this equipment are obtained. The optimal solutions found in the study of qualitative indices of the work process are combined with the optimal solutions obtained in the statistical analysis of the energy and economic indices, thus obtaining the optimal working regimes, both in terms of qualitative, as well as quantitative.
\end{abstract}

Keywords: quality indices, draft tillage forces, furrows equipment, experimental research.

\section{Introduction}

Experimental research is indispensable for current general research. The advance of theories vertically (in depth) and horizontally (diversification) cannot take place without experiments necessary, first of all, for theoretical modelling, and secondly, for validation. Agricultural sciences and, in particular the field of agricultural mechanization are closely linked to the experiment.

The advantages that irrigation through compartmentalized canals provides for some types of agricultural crops, [1], [8-11], have been a challenge for their mechanized realization. The last decades have marked the appearance on the market of equipment for construction of such irrigation systems. Simultaneously, a series of studies and experimental researches appeared to solve the problems of these equipments and to optimize their work regime, [2 - 7]. The study presented in this article is a synthesis of the research from [2-7], establishing the premises of the theoretical approach.

\section{Materials and methods}

The experiments, which data are processed in this article, are described in $[4,7]$, and $[14,15]$. An image of the development of the experiments is given in Fig. 1, together with the processing result, i.e. the watering compartments and micro dams.

The experiments were performed in the test range of INMA Bucharest, in a reddish-brown forest type soil, characterized by a penetration resistance between 3.93 and $15.33 \mathrm{MPa}$ and humidity between 9.6 and $19.1 \%$. The sides of the section polygon produced by the passage of the working members of the equipment through the ground, as well as the stresses in certain bars of the load-bearing structure were measured. From the tensometric records, the average values of the total force and on the palette generated by the resistance to soil processing were deduced. Tensometric measurements were made for four working speeds between 2.16 and $3.17 \mathrm{~km} \cdot \mathrm{h}^{-1}$. The experiments were performed with two variants of EOCFW, Fig. 2. 


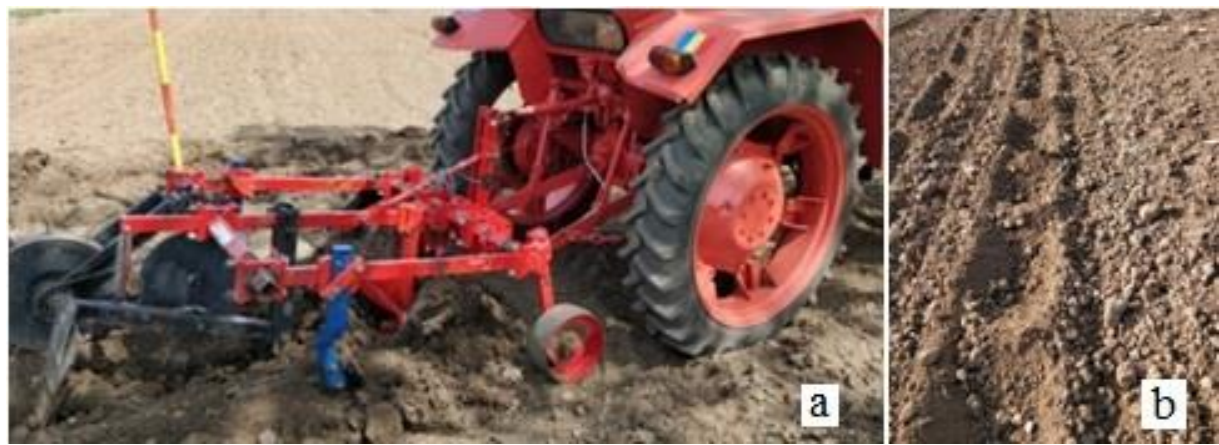

Fig. 1. Experimental activity: a -working aggregate; $b$ - channels and dams generated

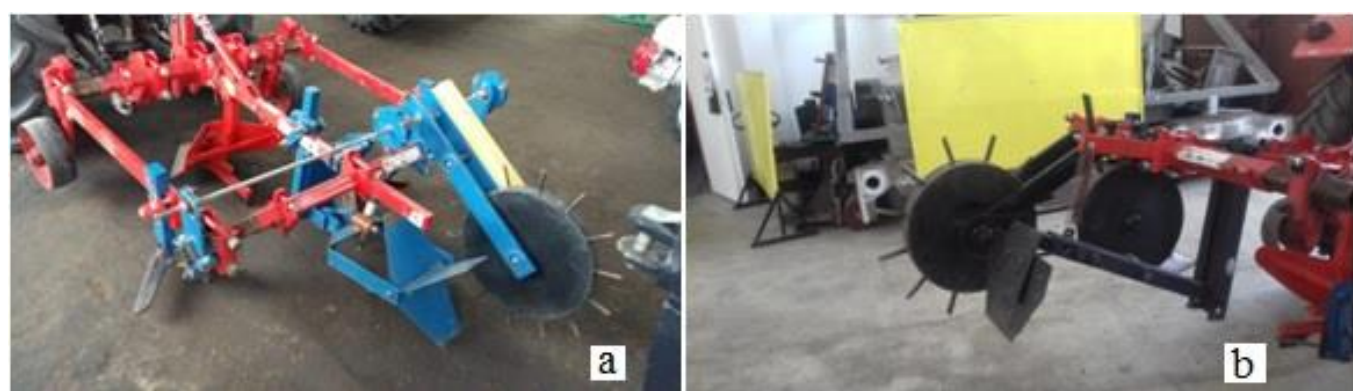

Fig. 2. Rotor version of the EOCFW load-bearing structure (a), and the cam version, (b)

The study contains descriptive statistical analysis of experimental data, inferential statistical analysis (statistical modelling) and models for components of the draft tillage force. By qualitative indices of the operation performed by the equipment for opening and compartmentalizing watering furrows (EOCWF) we will understand in this material the values that define the geometry of the EOCWF open channel profile and its length (Fig. 3): the depth of ditches $H_{d}$, the width of the bottom $B_{d}$, the upper width of the gutter $B_{b}$, the height of the mini dam $\mathrm{H}_{\mathrm{b}}$, the distance between mini dams $L_{d}$.

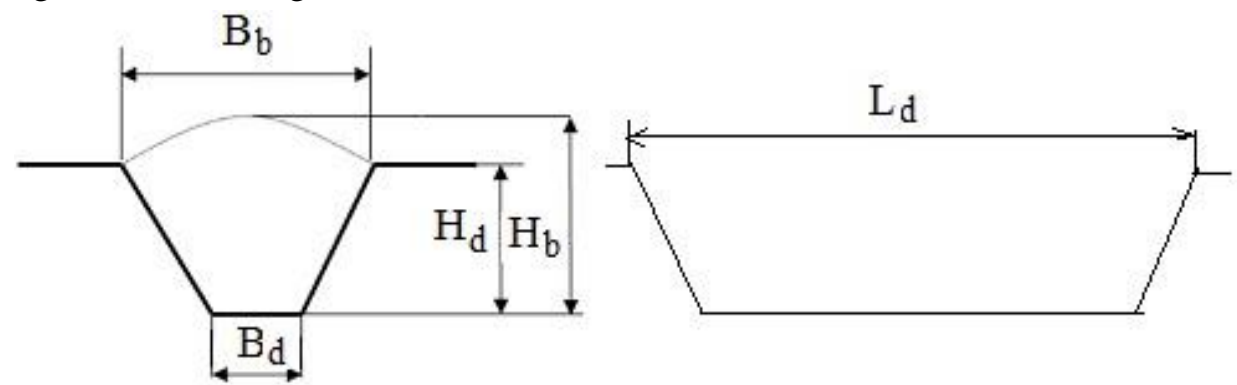

Fig. 3. Qualitative indices of the channel opening operation

\section{Results and discussion}

Statistical analysis meant the calculation of elementary statistical descriptors (mean values, deviations, median, symmetry and asymmetry estimators, vault estimators, minimum and maximum values and coefficients of variation). The main purpose of the EOCWF quality indexes study was to select the best of the eight variants tested (palettes: straight with initial dimensions, straight with optimized dimensions, inclined, curved, for two types of structures: rotor and cam). For each of the eight variants, the elementary statistical estimators were calculated, after which, for sorting, the scattering estimator was defined relative to the average value:

$$
\sigma_{r e l}=\frac{\sigma}{\mu} \cdot 100,
$$

where $\sigma$ and $\mu$-standard deviation and the mean value of the values of string of the qualitative indexes.

Based on the estimator (1) the global norm can be considered: 


$$
\sigma_{\text {reli }}=\sqrt{\sigma_{\text {relHbi }}^{2}+\sigma_{\text {relHdi }}^{2}+\sigma_{\text {relBbi }}^{2}+\sigma_{\text {relBdi }}^{2}+\sigma_{\text {relLdi }}^{2}}, i=1,2,3,4
$$

The results of the calculation of the global norm for the eight variants of EOCWF are synthetically represented in Fig. 4. It is observed that the optimal variants for each of the two categories of equipment (with cam, respectively with rotor) are obtained for the cases in which they are equipped with the straight blade with optimized dimensions. A very close relative spread to the two optimal cases is obtained for both equipments, in case of equipping the equipment with a curved palette. The best option of the eight is the cam equipment equipped with an optimized straight blade.

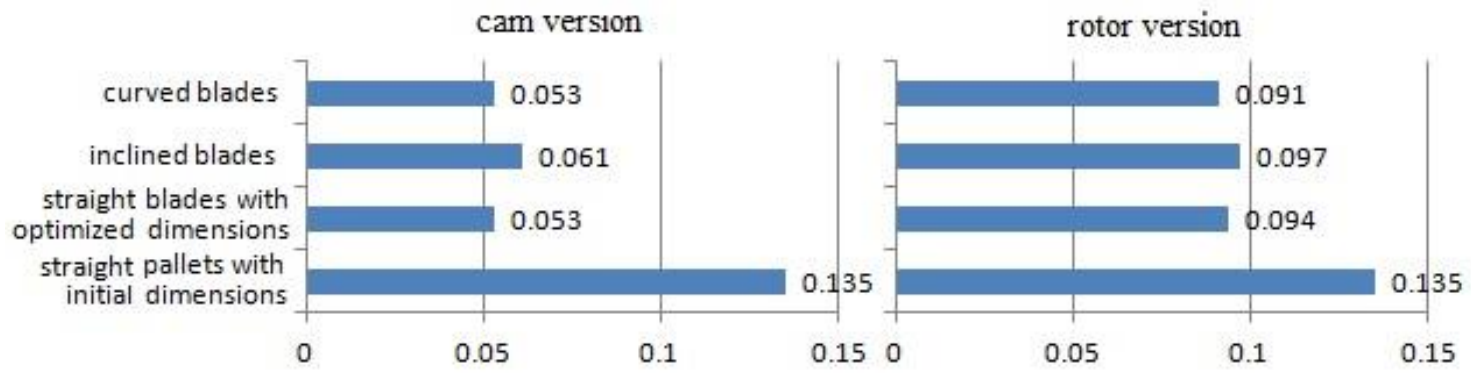

Fig. 4. Global relative spread (overall qualitative indices), for all work variants

For the forces of resistance to soil processing, measured in the experiments, the experimental data are summarized in Fig. 5 - 8. Fig. 5 graphically represents the dependencies of the total forces on the resistance to soil processing, on the working speed, the only freely varied parameter in the experiments, for EOCFW variant with the rotor. Fig. 6 graphically represents the dependence of the soil tillage draft force, generated by the blades from the four types, for EOCFW equipped with the rotor.

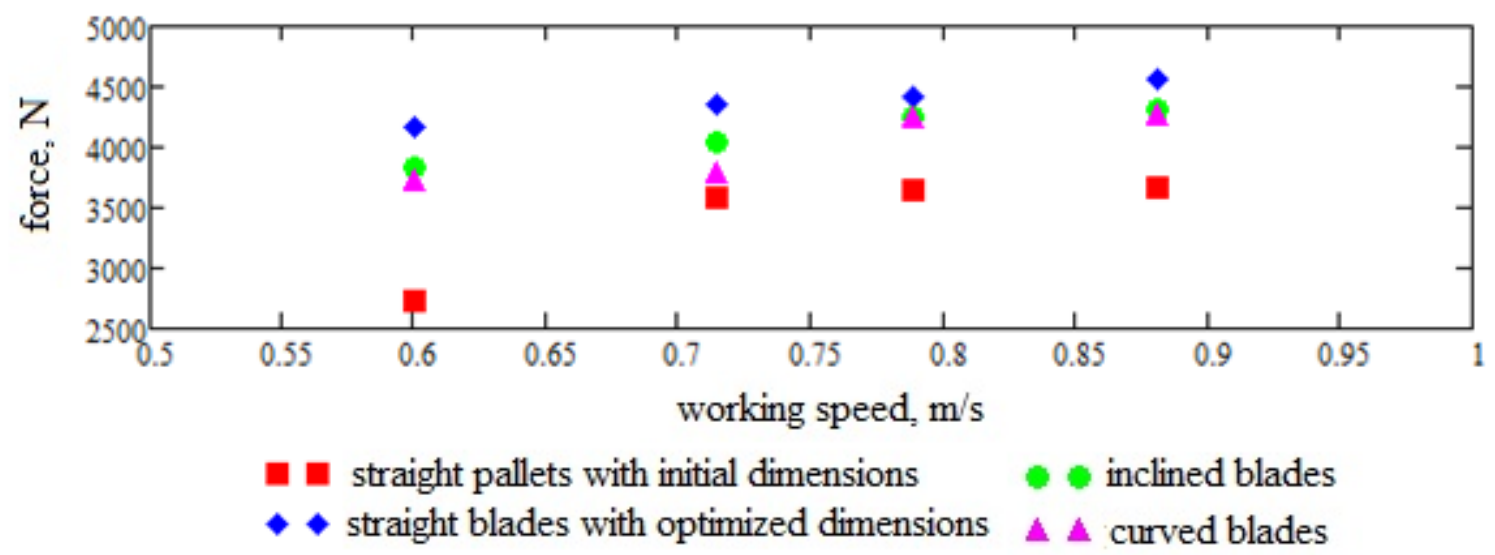

Fig. 5. Dependence of the total draft soil tillage force by the working speed, for EOCWF with a rotor

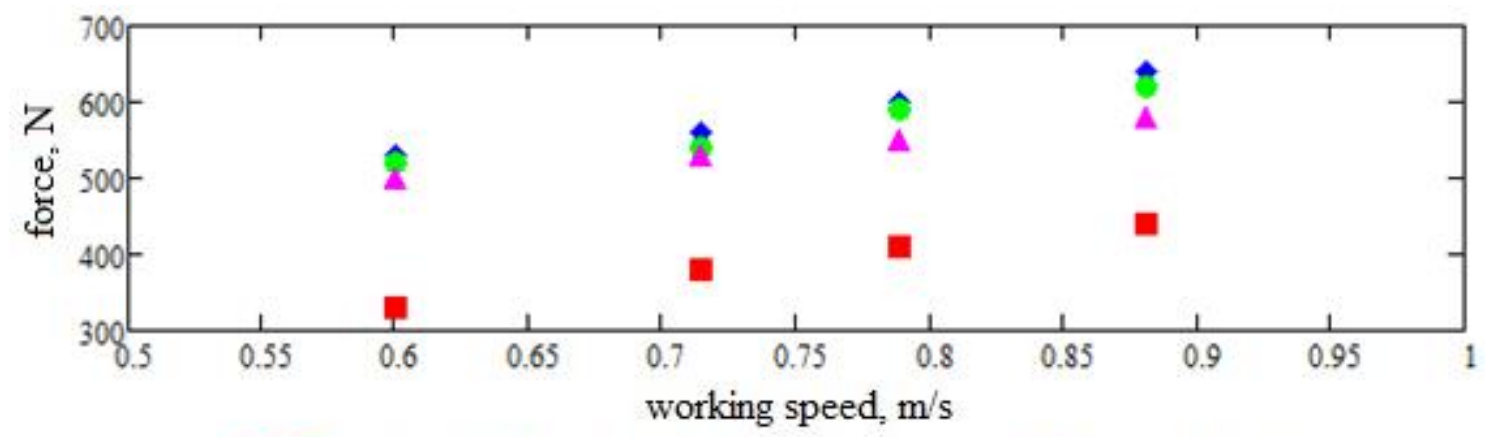

a straight pallets with initial dimensions $\quad$ inclined blades

- straight blades with optimized dimensions $\Delta *$ curved blades

Fig. 6. Soil draft tillage force dependence given by pallet, by the working speed, for EOCWF with a rotor 
Fig. 7 graphically represents the dependencies of the total forces on the resistance to soil processing, on the working speed, the only freely varied parameter in the experiments, for EOCFW variant with a cam. Fig. 8 graphically represents the dependence of the soil tillage draft force, generated by the blades from the four types, for EOCFW equipped with a cam.

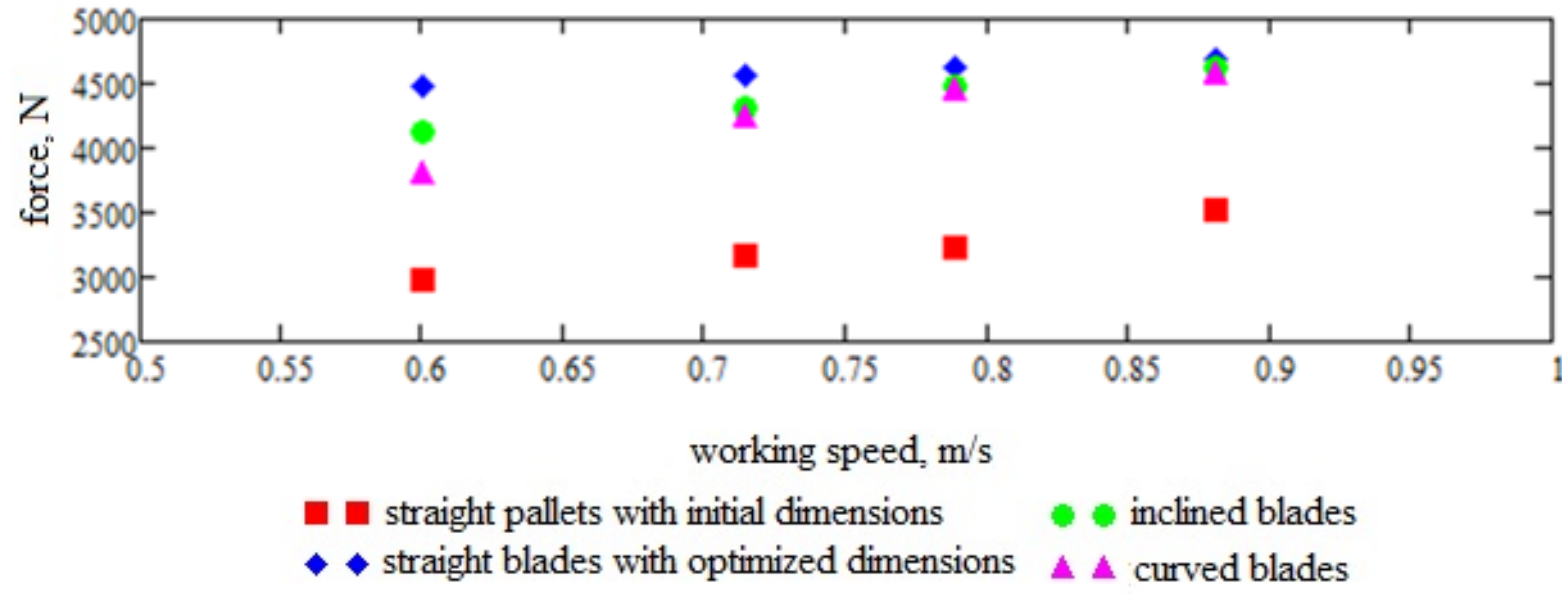

Fig. 7. Dependence of the total draft soil tillage force by the working speed, for EOCWF with a cam

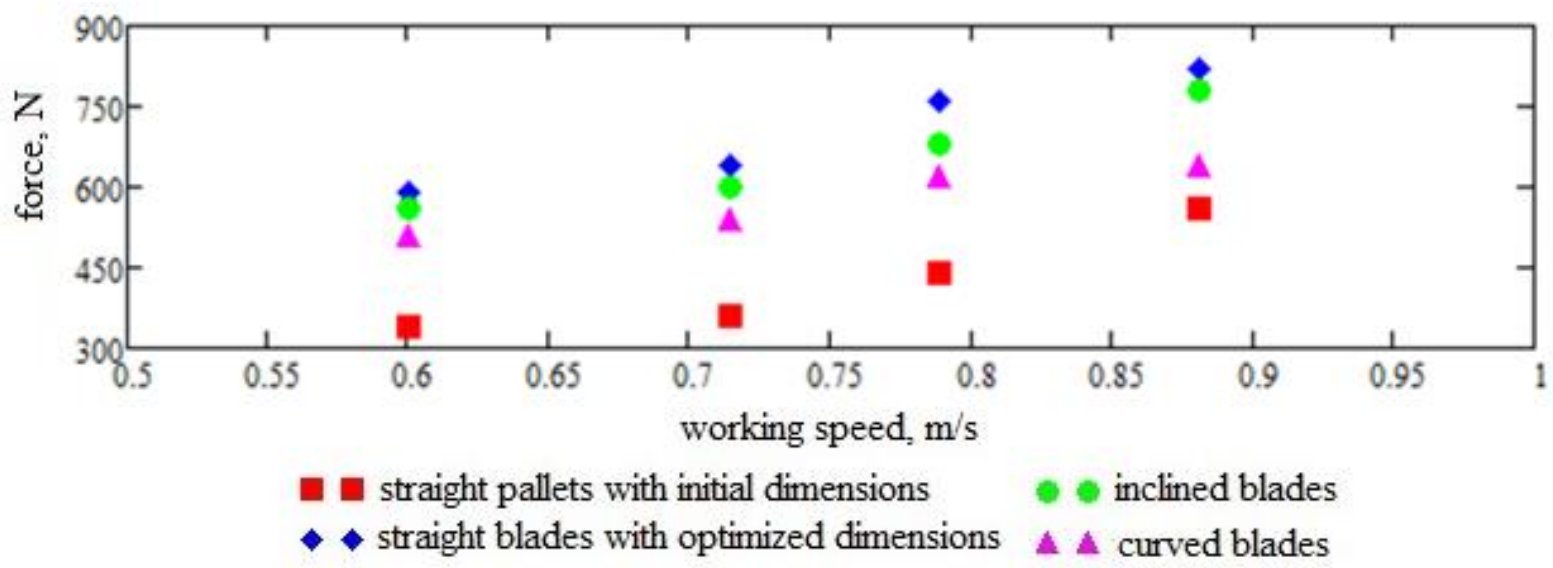

Fig. 8. Soil draft tillage force dependence given by pallet, by the working speed, for EOCWF with a cam

The data in Figs. 5-8 are part of the descriptive statistics of the data. On these data the classical estimators, the correlations, etc. are calculated. Starting from these data, we move on to statistical interpolation, obtaining the first results related to inferential statistics, of which two examples are given below.

Regarding the energy indices, the results of the estimation of the resistance forces to the tillage for the working variants mentioned above are presented. Taking into account that the forces of resistance to soil tillage were determined experimentally for both main working members, the rarity, and for the finishing working member, the palette, theoretical expressions for their approximation were established separately and a theoretical-empirical expression is possibly to be formulated for the total draft tillage force generated by the EOCWF. For example, for the rotor version of the EOCWF and a straight blade with initial dimensions, there is the next formula:

$$
R=428.841+271.079 v^{2} .
$$

Relationship (3) is of Goriacikin type, [12], customized to the conditions of the aggregate used and the environment (soil type, humidity, etc.). An alternative to classical second-degree polynomial models in the working speed, for the same working variant, is obtained using the formula proposed in [13]:

$$
F=x \rho\left(\frac{B_{b}+B_{d}}{2}\right)^{2} v^{2}\left(\frac{C+C_{a}}{\rho v^{2}}\right)^{y} \cdot\left(\frac{2 H_{d}}{B_{b}+B_{d}}\right)^{z} \cdot(\sin \alpha)^{t}
$$


where $x, y, z, t$ - process parameters, without physical dimension;

$\rho$ - soil density;

$\alpha$ - angle of the attack surface of the organ with respect to the soil surface;

$C$ - cohesion;

$C_{a}-$ soil adhesion.

In the case of the straight palette, because $\alpha=\pi / 2 \mathrm{rad}$, the parameter $\mathrm{t}$ has no influence, so it was removed from the calculation. For $C=15000 \mathrm{~Pa}, C_{a}=150 \mathrm{~Pa}, \rho=1000 \mathrm{~kg} \cdot \mathrm{m}^{-3}$, applying the method of least squares for the experimental data of the variant with a rotor and straight vane with initial dimensions, the values of the model parameters are obtained: $x=1.477, y=0.747, z=0.710$.

Expressions of type (3) or (4) can be obtained for all other EOCWF variants used in the experiments.

The soil processing quality indices of EOCWF can sort out the best work variant. The calculation formulas deduced for the soil tillage processing force, by the method described in this article, are recommended to be used only in the experimental working speed range. Extrapolating these formulas is risky. The correlations between the total processing strength of the equipment and the processing strengths on the pallet are high (over 0.9) with one exception of eight cases, in which it has the value 0.888. Therefore, the shape variation of the total machining strength of the equipment has the same shape as the variation of the shape of the machining strength on the adjusting or reinforcing working member (blade).

\section{Conclusions}

The obtained results are used for: the analysis of the qualitative indices of the work process, the establishment of the forces that require the load-bearing structure (structural analysis), the establishment of some calculation formulas for the tensile strength, useful in the calculation of energy balance.

The results of the descriptive statistics allowed the following conclusions to be drawn:

1. You can choose a more efficient solution than the others, having as objective the scattering of the quality indices compared to the average values, namely, the variant with a rotor with curved blades.

2. There are no obvious dependencies between the quality indices of the open profiles.

3. Reporting the section made for the open channel to a reference section, shows that the cam variant of EOCWF has a significantly better accuracy than the rotor version.

4. The shape and dimensions of the open channel section depend on the geometry of the blade and of the lister, the speed of movement of the aggregate and the properties of the soil.

Regarding the forces of resistance to tillage we note that:

5. For both equipment variants both in terms of the strength resistance to total processing and on the blade, the minimum values are obtained to the variant equipped with a curved blade and the maximum values to the straight blade with the initial dimensions.

6. The hierarchy of resistant forces corresponding to the four types of blades is kept at the equipment level (with rotor or cam), in ascending order, being the variants: with a curved blade, with an inclined blade, a straight blade with optimized sizes, a straight blade with initial sizes

\section{Acknowledgements}

This work was supported by a grant of the Romanian Research and Innovation Ministry, by "NUCLEU" Programme, developed with the support of the RRIM, project PN 19100102 and the Romanian National Authority for Scientific Research and Innovation, CNCS/CCCDI -UEFISCDI, project number PN-III-P1-1.2-PCCDI-2017- 0566 (ctr. No. 9 PCCDI/2018- COMPLEX SYSTEM OF INTEGRAL VALUABILITY OF AGRICULTURAL SPECIES WITH ENERGY AND FOOD POTENTIAL).

\section{References}

[1] Oprescu R.M., Voicea I.F., Dumitru I., Dragan I., Biolan C., Ungureanu N., Neagu E.A., Norbert B., Jaloba D., Arsenoaia V.N., Rain Use efficiency in Southern Romania after Using the Device for Soil Modelling in Interrupted Furrows for Weeding Crops- DMBC-5, E3S Web of Conferences 112, 03005, 2019. 
[2] Oprescu M.R., Biriș S.S., Marin E., Sorica C., Ungureanu N., Sorica E., Dumitru I., Grigore I., Considerations on mechanically active equipment for open interrupted furrow used in technology of weeding plant cultures fruit and viticultural plantations, ISB INMA-TEH, 2017, pp.215-220.

[3] Oprescu R., Biriș S.S., Voicea I., Vladuț V., Paraschiv G., Marinescu A.M., Considerations regarding the construction and operation of an equipment designed to model the soil in compartmented furrows in vineyards and orchards, ISB-INMA-TEH, 2018, pp. 431-436.

[4] Oprescu M.R., Dumitru D.N., Voicea I.F., Biris S.S., Considerations regarding the use of the equipment for opening and compartmentalizing the watering furrows, ISB-INMA-TEH, 2019, pp.388-393.

[5] Oprescu M.R., Biriș S.S., Voicea I., Cujbescu D., Gageanu I., Dumitru I., Considerations on the construction and operation of a device for soil modelling in interrupted furrows for weeding crops, TE-RE-RD, 2018, pp. 309-314.

[6] Oprescu M.R., Gageanu I., Cristea M., Determining the qualitative working indices for various forms of the active body of a rut soil compartmentation equipment, E3S Web of Conferences 180, 03011, 2020. $10 \mathrm{p}$.

[7] Oprescu R., Dumitru D., Dumitru I., Angelache D., Biriș S.S., Verificarea modului de realizare a indicilor calitativi obținuți la compartimentarea brazdelor de udare după utilizarea dispozitivului de modelat solul în brazde compartimentate la culturile prășitoare-dmbc5, ISB-INMA-TEH, 2020, pp. 563-570.

[8] Malesu M.M., Oduor A. R., Odhiambo O.J., Green Water Management Handbook, Rainwater harvesting for agricultural production and ecological sustainability, ICRAF House, 2007. 219 p.

[9] Colburn A. E.; Alexander U.U., Furrow Diking in Texas.Texas Agricultural Experiment Station. Available electronically from $\mathrm{http}: / \cdot \mathrm{h}^{-1} \mathrm{dl}$.handle .net $/ 1969.1 / 129146,1986.8 \mathrm{p}$.

[10] Ventura E., Soil Structure and the Science of TerraStar, Queretaro, 2017.

[11] Olivier C., Goffart J.P., Baets D., Fonder N., Barthélemy J.P., Lognay G., D. Xanthoulis, Le cloisonnement des interbuttes en culture de pomme de terre: essai réalisé en collaboration avec Bayer CropScience, Huldenberg, 2011. 7 p.

[12] Letosnev M.N., Masini Agricole, Ministerul Agriculturii si Silviculturii, Editura Agro-Silvica de Stat, Bucuresti, 1959.

[13] American Society of Agricultural Engineers [ASAE]. 2003a. D497.4 Agricultural machinery management data. In: ASAE. ASAE standards, St. Joseph, MI, USA, 2003, pp. 373-380.

[14] Cujbescu D., Vlăduţ V., Voicu Gh., Ungureanu N., Researches on obtaining higher qualitative indices for the sowing work, 15th International Scientific Conference "ENGINEERING FOR RURAL DEVELOPMENT”, Proceedings, vol. 15, ISSN 1691-5976, 2016, pp: 1305-1311.

[15] Vlăduţ D.I., Vlăduţ V., Grigore I., Biriş S., Experimental research on qualitative indices of work for equipment for seedbed preparation in conservative system, 16th International Scientific Conference "ENGINEERING FOR RURAL DEVELOPMENT", ISSN 1691-5976, 2017, pp. 1174-1179. 